\title{
A Gasometric Procedure to Measure Residual Lime in Container Substrates
}

\author{
Jinsheng Huang \\ Department of Plant Biology, University of New Hampshire, Durham, NH \\ 03824
}

Paul R. Fisher ${ }^{1}$
Department of Environmental Horticulture, 2549 Fifield Hall, University of
Florida, P.O. Box 110670, Gainesville, FL 32611-0670

William R. Argo

Blackmore Co., 10800 Blackmore Avenue, Belleville, MI 48111

Additional index words. alkalinity, $\mathrm{CaCO}_{3}$, bicarbonate, carbonate, limestone, peat, $\mathrm{pH}$, residual, substrate-pH

\begin{abstract}
Unreacted residual limestone in the container substrate is key in buffering $\mathbf{p H}$ change over time. Our goal was to develop a substrate test protocol to measure residual lime [in units of $\mathrm{CaCO}_{3}$ equivalent (CCE)] by applying a strong mineral acid (HCI) to a substrate sample and measuring the evolved $\mathrm{CO}_{2}$ gas with a gasometric method based on a Chittick apparatus. In one experiment, $\mathrm{CaCO}_{3}$ was added to a substrate that had previously been neutralized to $\mathrm{pH} 7.35$ with $\mathrm{Ca}(\mathrm{OH})_{2}$ so that there would be minimal $\mathrm{CaCO}_{3}$ reaction with the substrate at this high $\mathrm{pH}$. The gasometric method was then used to estimate residual $\mathrm{CCE}$. Measured $\mathrm{CCE}$ and applied $\mathrm{CaCO}_{3}$ were similar, indicating reliable CCE estimation. In a second experiment, a $\mathrm{pH}$ titration method was used to quantify the relationship between substrate-pH and milliequivalents of reacted base and provided an additional validation of the estimated reacted and residual CCE. The gasometric method demonstrated declining residual $\mathrm{CCE}$ over time as a dolomitic limestone reacted to raise substrate-pH and increasing residual $\mathrm{CCE}$ as applied $\mathrm{CaCO}_{3}$ concentration increased. Residual CCE in a substrate is an important property that should be considered for $\mathrm{pH}$ control and management in greenhouse crop production. Our results indicate that the gasometric system may be useful for optimizing lime application rate, lime source, or management of residual CCE during crop production.
\end{abstract}

Liming materials are incorporated into container substrates to neutralize acidity and to provide calcium $(\mathrm{Ca})$ and magnesium $(\mathrm{Mg})$. Liming materials differ in their reactivity rate, which in turn determines the proportion of base that remains as unreacted "residual" limestone in the substrate. Research has shown that most $\mathrm{pH}$ buffering in container substrates comes from residual lime (Argo and Biernbaum, 1996). However, a test method is currently lacking to quantify the concentration of residual lime [in units of calcium carbonate $\left(\mathrm{CaCO}_{3}\right)$ equivalents $(\mathrm{CCE})]$ in container substrates.

The most common liming materials used in greenhouse substrates are carbonate-based

Received for publication 21 Feb. 2007. Accepted for publication 21 May 2007.

We thank the American Floral Endowment, Blackmore Co., Center Greenhouses, D. S. Cole Growers, Ellegaard, Greencare Fertilizers, KubePak Corp., Lucas Greenhouses, Pleasant View Gardens, Premier Horticulture, Quality Analytical Laboratories, Sun Gro Horticulture, and the UNH Agricultural Experiment Station for financial support of this project.

The use of trade names in this publication does not imply endorsement of the products named or criticism of similar ones not mentioned.

${ }^{1}$ To whom reprint requests should be addressed; e-mail PFisher@ufl.edu. limestones: calcite $\left(\mathrm{CaCO}_{3}\right.$ with $\left.40 \% \mathrm{Ca}\right)$, calcitic $\left[\mathrm{CaMg}\left(\mathrm{CO}_{3}\right)_{2}\right.$ with greater than $30 \%$ $\mathrm{Ca}$ and less than $5 \% \mathrm{Mg}$, dolomitic $\left[\mathrm{CaMg}\left(\mathrm{CO}_{3}\right)_{2}\right.$ with less than $30 \% \mathrm{Ca}$ and greater than $5 \% \mathrm{Mg}]$, and dolomite [CaMg $\left(\mathrm{CO}_{3}\right)_{2}$ with $22 \% \mathrm{Ca}$ and $13 \% \mathrm{Mg}$. When carbonate-based limestones react with acid from proton sources such as acidic peat, then calcium $\left(\mathrm{Ca}^{2+}\right)$ or magnesium $\left(\mathrm{Mg}^{2+}\right)$, water $\left(\mathrm{H}_{2} \mathrm{O}\right)$, and carbon dioxide $\left(\mathrm{CO}_{2}\right)$ gas result:

$$
\begin{aligned}
\mathrm{CaCO}_{3}(\text { calcite })+2 \mathrm{H}^{+} \leftrightarrow & \mathrm{Ca}^{2+}+\mathrm{H}_{2} \mathrm{O} \\
& +\mathrm{CO}_{2}(\text { gas })
\end{aligned}
$$

$$
\begin{gathered}
\mathrm{CaMg}\left(\mathrm{CO}_{3}\right)_{2} \text { (dolomite) }+4 \mathrm{H}^{+} \leftrightarrow \mathrm{Ca}^{2+} \\
+\mathrm{Mg}^{2+}+2 \mathrm{H}_{2} \mathrm{O}+2 \mathrm{CO}_{2} \text { (gas) }
\end{gathered}
$$

Our hypothesis, based on research measuring CCE in agronomic soils (Dreimanis, 1962; Hülsemann, 1966), was that the unreacted lime concentration (on the left side of Eqs. 1 and 2) could be determined in a soilless substrate by addition of a strong acid and subsequent measurement of released $\mathrm{CO}_{2}$ gas through volume displacement. The volume of $\mathrm{CO}_{2}$ gas evolved by the chemical reaction can be determined with a Chittick apparatus (or variants thereof), which is easily constructed from basic laboratory glassware and tubing (Fig. 1; Dreimanis, 1962). Once the device is calibrated by use of prepared $\mathrm{CaCO}_{3}$ standards, 1) media samples are introduced and reacted with $\mathrm{HCl}, 2$ ) the volume of $\mathrm{CO}_{2}$ released is measured, and 3) the amount of residual lime is calculated with either a $\mathrm{CO}_{2}-\mathrm{CaCO}_{3}$ standard curve or the Ideal Gas Law with a known air temperature and air pressure.

Soil CCE content can be determined by either measuring the $\mathrm{CO}_{2}$ evolved when treated with acid or the use of empirical standard curves relating $\mathrm{pH}$ to known carbonate content. The first method includes several procedures differing in how evolved $\mathrm{CO}_{2}$ is quantified. The liquid displacement (i.e., Chittick) method on which our technique is based has been widely used (Dreimanis, 1962; Hülsemann, 1966) to measure the volume of $\mathrm{CO}_{2}$ evolved on application of strong acid. The gravimetric method for measuring $\mathrm{CaCO}_{3}$ (Allison and Moodie, 1965 ) is another well-known procedure and appears in other soil analysis manuals (Goh et al., 1993). In the gravimetric procedure for measuring $\mathrm{CaCO}_{3}$, a soil sample is combined with excess $4 \mathrm{M} \mathrm{HCl}$ and the loss in weight incited by $\mathrm{CO}_{2}$ evolution is converted to $\mathrm{CCE}$ using an equation based on formula weights. The gravimetric method uses an Erlenmeyer flask as the reaction vessel and involves periodically removing and replacing a rubber stopper while the flask is swirled to promote $\mathrm{CO}_{2}$ evolution. Loss of $\mathrm{H}_{2} \mathrm{O}$ vapor along with $\mathrm{CO}_{2}$ contributes to the loss in weight each time the stopper is removed and thus increases the calculated CCE content. A resolution problem can also occur because the flask and stopper together weigh well over $100 \mathrm{~g}$ along with a soil sample of 1 to $10 \mathrm{~g}$, whereas the loss in weight for a typical soil is only tenths of a gram.

The second method involves the reaction of the soil carbonates with $0.4 \mathrm{M}$ acetic acid and then measuring $\mathrm{pH}$ after allowing the acid-soil solution time to reach equilibrium. The $\mathrm{pH}$ value is converted to an equivalent $\mathrm{CaCO}_{3}$ content by means of an algorithm obtained in separate calibration runs with pure $\mathrm{CaCO}_{3}$ (Moore et al., 1987). The problem mentioned by Moore et al. (1987) is that appreciable $\mathrm{CaCO}_{3}$ content can be estimated even for acidic soils, apparently as a result of neutralization of dilute acetic acid by clay and organic matter.

Our goal was to develop and test a gasometric method for quantifying residual lime in a container substrate and describe a recommended protocol. To improve confidence that the gasometric method was a valid approach, specific objectives were to compare estimated CCE against 1) applied $\mathrm{CaCO}_{3}$ under high $\mathrm{pH}$ conditions, and 2) a $\mathrm{pH}$ titration method to relate substrate- $\mathrm{pH}$ with milliequivalents of reacted $\mathrm{CaCO}_{3}$. The method was then used to quantify the effect of 3) dolomitic limestone on residual CCE and substrate-pH over time, and 4) increasing applied $\mathrm{CaCO}_{3}$ on residual $\mathrm{CCE}$ and substrate$\mathrm{pH}$. Additional experiments were run to identify potential sources of measurement 
error. The conclusion of this article describes a recommended protocol.

\section{Materials and Methods}

The gasometric system. A gasometric system adapted from a Chittick device (Dreimanis, 1962) was described by Huang et al. (2007) for measuring the reaction rate of different carbonate limestone sources and particle size fractions (Fig. 1). The gasometric system consisted of a gas-measuring burette, acid-dispensing burette, level burette, 1-L decomposition flask, and a magnetic stirrer. $\mathrm{CaCO}_{3}$ equivalent was calculated based on volumetric measurement of $\mathrm{CO}_{2}$ through displacement of a solution in the measuring burette.

The $\mathrm{CO}_{2}$ volume could be related to moles of $\mathrm{CaCO}_{3}$ using the Ideal Gas Law:

$$
\mathrm{N}_{\mathrm{CO} 2}=\mathrm{P}_{\mathrm{CO} 2} \mathrm{~V}_{\mathrm{CO} 2} / \mathrm{RT}
$$

where $\mathrm{N}_{\mathrm{CO} 2}$ represents the moles of $\mathrm{CO}_{2}$ liberated $\left(\mathrm{N}_{\mathrm{CO} 2}\right.$ also equals the moles of carbonate material decomposed according to the stochiometry of Eqs. [1] and [2]), $\mathrm{P}_{\mathrm{CO} 2}$ represents $\mathrm{CO}_{2}$ partial pressure $(\mathrm{Pa})$, $\mathrm{V}_{\mathrm{CO} 2}$ represents the volume of $\mathrm{CO}_{2}$ (L) liberated after subtracting the volume of $\mathrm{HCl}$ from the displaced gas volume, $\mathrm{R}$ is

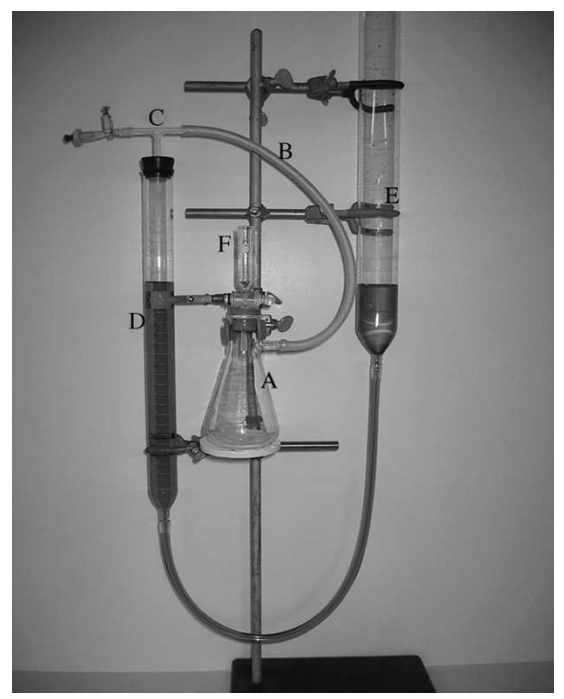

Fig. 1. A gasometric system for $\mathrm{CO}_{2}$ measurement adapted from Chittick apparatus [AOAC Official Method 923.02; diagram from Huang et al. (2007)]. The decomposition flask (A) was connected through the side hose connection by rubber tube (B) provided with a stopcock (C) to a graduated gas-measuring burette (D), which was connected in turn with a level burette (E) using a rubber tube. To measure residual carbonate lime in the substrate, a $1-\mathrm{L}$ wide-mouth filter flask (A) was fitted with a one-hole rubber stopper with an extended tip of a $10-\mathrm{mL}$ acid-dispensing burette $(\mathrm{F})$ passed through the hole. A magnetic stirrer (not shown here) was also introduced into the gasometric system for residual lime measurement. A heat isolation pad should be placed between the top surface of the stirrer and the bottom of the decomposition flask to isolate possible heat from the magnetic stirrer motor. the universal gas constant $(0.008314$ $\left.\mathrm{L} \cdot \mathrm{Pa} \cdot \mathrm{K}^{-1} \cdot \mathrm{mol}^{-1}\right)$, and $\mathrm{T}$ is temperature $(\mathrm{K})$ $\left({ }^{\circ} \mathrm{C}+273.2\right)$.

Initial calibration of the system. The precision and accuracy of estimated $\mathrm{CaCO}_{3}$ was tested by comparing estimated $\mathrm{CaCO}_{3}$ against a weighed amount of $\mathrm{CaCO}_{3}$ (Fig. 2) ranging from 0.01 to $8.0 \mathrm{mmol}(0.001-0.8$ g). For each measurement, $0.005 \mathrm{~L}$ of $6 \mathrm{M}$ $\mathrm{HCl}$ was added to the decomposition flask to react with the standard $\mathrm{CaCO}_{3}$. The volume of $\mathrm{CO}_{2}$ was recorded after complete $\mathrm{CaCO}_{3}$ reaction, with a 5-min reaction time, subtracting the volume of the $\mathrm{HCl}$ from the displaced gas volume.

Overall, the system accurately and precisely measured $\mathrm{CaCO}_{3}$ (Fig. 2A-B) when the sample was $\mathrm{CaCO}_{3}$ (without substrate). The device successfully determined $\mathrm{CaCO}_{3}$ content as low as $0.01(0.001 \mathrm{~g})$ up to 8.0 $(0.8 \mathrm{~g}) \mathrm{mmol}$, although errors occurred when standard $\mathrm{CaCO}_{3}$ was less than $0.5 \mathrm{mmol}(0.05$ $\mathrm{g}$ ) in the sample (Fig. 2A). If the system was used to measure lime incorporated into a substrate, 0.01 to $8.0 \mathrm{mmol}$ would be equivalent to $\mathrm{CCE}$ at 0.02 to $16 \mathrm{~g} \cdot \mathrm{L}^{-1}(0.02$ $16 \mathrm{~kg} \cdot \mathrm{m}^{-3}$ ) of substrate for a sample volume of $0.050 \mathrm{~L}$ of substrate.

To measure residual lime incorporated into a peat-based substrate, the gasometric system needed to be further calibrated. To do this, subsamples of an experimental substrate composed of $70 \%$ peat $+30 \%$ perlite by volume were measured in $0.05-$ or $0.1-\mathrm{L}$ sample volumes in a beaker with the substrate packed to similar bulk density as would occur in an irrigated and drained container. The peat source used in all experiments was Canadian Sphagnum peat (Sun Gro Horticulture, Vancouver, Canada) with long fibers and little dust (Von Post scale 1-2; Puustjarvi and Robertson, 1975). These subsamples were placed into 1-L decomposition flasks. The dry bulk density for peat and $70 \%$ peat + $30 \%$ perlite was 128 and $147 \mathrm{~g} \cdot \mathrm{L}^{-1}$, respectively. The medium contained $150 \mathrm{~mL}$ water per liter before analysis. Deionized water was added to the substrate at 1.5 times the sample volume (i.e., 0.075 or $0.15 \mathrm{~L}$ for the substrate sample of 0.05 or $0.1 \mathrm{~L}$, respectively). The flask was then attached to the gasometric system. The system was closed and $6 \mathrm{M} \mathrm{HCl}$ was introduced into the decomposition flask at half the sample volume $(0.025-$ or $0.05-\mathrm{L}$ aliquot of $6 \mathrm{M} \mathrm{HCl}$ for 0.05 - or 0.1 -L substrate samples, respectively). The sample in the flask was constantly stirred using a magnetic stirrer, and a heat isolation pad was placed between the top surface of the stirrer and the bottom of the decomposition flask. The reaction time was $10 \mathrm{~min}$ for reagent $\mathrm{CaCO}_{3}$ and $30 \mathrm{~min}$ (Dreimanis, 1962) for horticultural limestone. After reaction, the apparatus was left to stand for $2 \mathrm{~min}$ for temperature and pressure within the apparatus to reach room conditions. The temperature and barometric pressure of air surrounding the apparatus was then measured.

The amount of residual lime can be calculated using either the Ideal Gas Law with a known air temperature and air pressure or with a $\mathrm{CO}_{2}-\mathrm{CaCO}_{3}$ standard curve. The standard curve appropriate to residual CCE measurement was generated by adding a range in weights of $\mathrm{CaCO}_{3}$ to the decomposition flask along with a fixed volume of deionized water rather than with a fixed volume of container substrate. Standard weights of $\mathrm{CaCO}_{3}$ of $0,0.02,0.05,0.10$, 0.20 , and $0.30 \mathrm{~g}$ were added to the decomposition flasks followed by a given volume of deionized water $(0.075$ or $0.15 \mathrm{~L}$ for a corresponding substrate sample size of 0.05 or $0.1 \mathrm{~L}$, respectively) in a factorial manner.

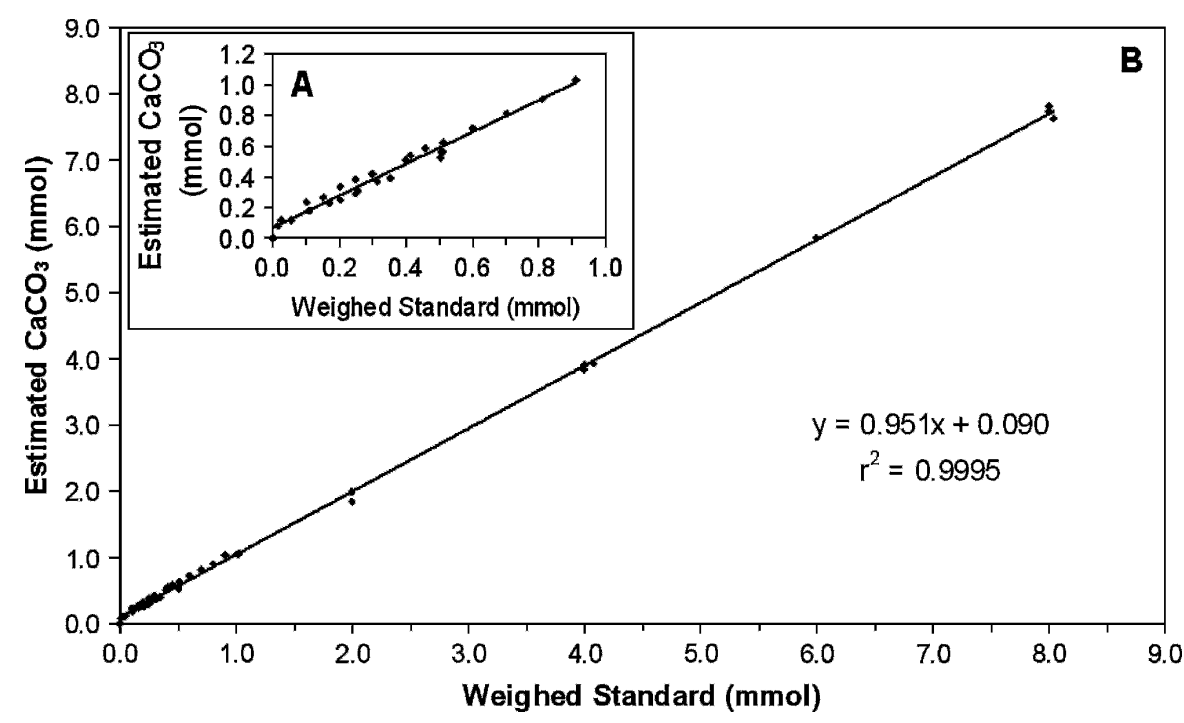

Fig. 2. Calibration of the gasometric system using reagent $\mathrm{CaCO}_{3}$. Reagent $\mathrm{CaCO}_{3}$ was weighed to the nearest $0.1 \mathrm{mg}$, ranging from 0.0 to $8.0 \mathrm{mmol}(0.8 \mathrm{~g})$, and was introduced into the decomposition flask without peat substrate. For each measurement, $0.005 \mathrm{~L}$ of $6 \mathrm{M} \mathrm{HCl}$ was added to the decomposition flask to react with the standard, and the volume of $\mathrm{CO}_{2}$ was recorded until complete reaction. (A) Detailed view for standard $\mathrm{CaCO}_{3}$ at low weights below $1.0 \mathrm{mmol}$. (B) The relationship between the estimated and weighed $\mathrm{CaCO}_{3}$ for the complete range in sample weights (0-8.0 mmol). Symbols represent individual measurements. 
The flask was then attached to the gasometric system and an aliquot of $6 \mathrm{M} \mathrm{HCl}$ (i.e., 0.025 or $0.05 \mathrm{~L}$ of $6 \mathrm{M} \mathrm{HCl}$ for corresponding substrate sample size of 0.05 or $0.1 \mathrm{~L}$, respectively) was added for complete $\mathrm{CaCO}_{3}$ reaction. After $10 \mathrm{~min}$ of reaction time, the volume of released $\mathrm{CO}_{2}$ was recorded and was plotted as a function of corresponding standard $\mathrm{CaCO}_{3}$ weight. During the course of residual CCE measurement, the room air temperature was kept stable, and the air pressure was assumed constant. For each experiment and substrate sample size, a different set of standard curves were developed, which were used in the analysis described in the figures. However, the calculated CCE using a standard curve $\left(\mathrm{CCE}_{\mathrm{S}}\right)$ and the calculated $\mathrm{CCE}$ using the Ideal Gas Law $\left(\mathrm{CCE}_{\mathrm{I}}\right)$ were very similar. Over all the experiments, the $\mathrm{r}^{2}$ equaled 0.999 for the relationship $\mathrm{CCE}_{\mathrm{S}}=$ $(1.032 \pm 0.015)^{*} \mathrm{CCE}_{\mathrm{I}}-(0.109 \pm 0.031)$.

After initial calibration of the system, we validated results using the following two methods.

A. Validation by incorporating reagentgrade $\mathrm{CaCO}_{3}$ into a preneutralized substrate. By adding $\mathrm{CaCO}_{3}$ to a substrate that was already at a high $\mathrm{pH}$, we expected minimal lime reaction. Therefore, the applied $\mathrm{CaCO}_{3}$ should be similar to the measured CCE, and this would provide a validation of $\mathrm{CCE}$ measurements. $\mathrm{CaCO}_{3}$ was incorporated at three concentrations $(0.5,1.0$, or $2.0 \mathrm{~g}$ per liter of substrate) into a $70 \%$ peat $+30 \%$ perlite (by volume) substrate that had been previously neutralized to $\mathrm{pH} 7.35$ (tested using the saturated medium extract method) using reagent $\mathrm{Ca}(\mathrm{OH})_{2}\left(2.7 \mathrm{~g} \cdot \mathrm{L}^{-1}\right)$. Residual $\mathrm{CCE}$ measurement occurred less than $6 \mathrm{~h}$ after $\mathrm{CaCO}_{3}$ incorporation, further reducing the likelihood that $\mathrm{CaCO}_{3}$ would react in the substrate. The residual CCE in the substrate was quantified both before and after $\mathrm{CaCO}_{3}$ incorporation by the gasometric method. The residual $\mathrm{CCE}$ contributed by the added $\mathrm{CaCO}_{3}\left(\mathrm{~g} \cdot \mathrm{L}^{-1}\right)$ was calculated as the difference in $\mathrm{CCE}$ before and after $\mathrm{CaCO}_{3}$ incorporation. The residual CCE measurement was compared against the $\mathrm{CaCO}_{3}$ incorporation rate to quantify the percent recovery by the gasometric method. Two substrate sample volumes of 0.05 or $0.1 \mathrm{~L}$ were selected to determine whether accuracy of the system would be affected by sample volume. Sample volume and lime rate combinations were replicated three times.

B. Validation against a $\mathrm{pH}$ titration procedure. Titration of peat-based substrate with $\mathrm{Ca}(\mathrm{OH})_{2}$ shows an approximately linear $\mathrm{pH}$ response with increasing application rate of base up to a $\mathrm{pH}$ near 7.0 (Rippy and Nelson, 2005). We also observed a linear trend using both the $\mathrm{Ca}(\mathrm{OH})_{2}$ and microfine $\mathrm{CaCO}_{3}(100 \%$ passing a 325 -mesh screen; unpublished data). Substrates vary in their buffering capacity, which can be quantified using a linear relationship [Eq. 4]:

$$
\mathrm{pH}=m+n * b
$$

where $m$ represents the offset (nonlimed substrate-pH), $n$ is the gradient [buffering capacity, in units of $\Delta \mathrm{pH} /\left(\mathrm{meq}\right.$ of $\mathrm{CCE} \cdot \mathrm{L}^{-1}$ of substrate)], and $b$ is the applied CCE in units of meq. $\mathrm{L}^{-1}$ of substrate. At any given substrate-pH value and substrate, the milliequivalents of CCE $(b)$ required to neutralize that amount of substrate acidity can be calculated from the titration curve [Eq. 5]:

$$
b=(\mathrm{pH}-m) / n
$$

If a known weight of limestone $(a)$ in CCE at meq. $\mathrm{L}^{-1}$ were applied to the substrate and $\mathrm{pH}$ measured, the reacted $\mathrm{CCE}$ at meq $\cdot \mathrm{L}^{-1}$ is represented by $b$ from Eq. 5, and the residual $\mathrm{CCE}$ at meq. $\mathrm{L}^{-1}$ is represented by $a$ minus $b$. A titration curve can therefore be used as a validation against measurements with the gasometric system.

A $70 \%$ peat $+30 \%$ perlite (without any preplant nutrient charge) was used to develop a $\mathrm{pH}$ titration curve for CCE estimation. The standard curve was prepared by weighing samples of reagent $\mathrm{CaCO}_{3}$ to the nearest 0.01 $\mathrm{g}$ and incorporating into $1 \mathrm{~L}$ of the substrate. Standards contained $\mathrm{CaCO}_{3}$ in weights of 0 , $0.58,1.75,2.93$, or 4.10 g. Deionized water was added to the substrate to raise moisture level to $\approx 95 \%$ container capacity. The substrate mixture was put in an open plastic bag to allow for gas exchange and was maintained at $22{ }^{\circ} \mathrm{C}$. Substrate-pH was measured with three replicates $3 \mathrm{~d}$ after lime incorporation. A pH titration curve was developed by plotting the average $\mathrm{pH}$ versus the corresponding $\mathrm{CaCO}_{3}$ rate.

A superfine dolomitic carbonate limestone $\left[99.5 \% \mathrm{CaMg}\left(\mathrm{CO}_{3}\right)_{2}\right.$; National Lime and Stone, Findlay, $\mathrm{OH}$; with a neutralizing value of $106.9 \%$ CCE] was screened to the fraction that passed through a 100-US mesh but was retained on a $200-U S$ mesh (75-150 $\mu \mathrm{m})$. The limestone was incorporated into the same $70 \%$ peat $/ 30 \%$ perlite (volume/volume) substrate for which the titration curve had been generated. Lime samples of 1.42, 2.86, or $5.71 \mathrm{~g}$ CCE were blended with $1 \mathrm{~L}$ of substrate. A total of $0.1 \mathrm{~L}$ of deionized water (equivalent to $20 \%$ container capacity) was added in the 1-L substrate after lime incorporation. Moisture content was maintained at only $20 \%$ container capacity to slow down the lime reaction rate and allow measurement over a period of days. The substrate was placed in open plastic bags at $22{ }^{\circ} \mathrm{C}$, and gasometric and substrate- $\mathrm{pH}$ measurements were used to quantify unreacted residual CCE in the substrate $1,2,8$, and $27 \mathrm{~d}$ after limestone incorporation. Each time residual CCE was measured, a $0.05 \mathrm{~L}$ of substrate sample was transferred into the 1-L decomposition flask, $0.05 \mathrm{~L}$ of deionized water was then added to the flask, and the substrate-pH was immediately measured using an Orion Model 620 (Thermo Electron Co., Waltham, MA) $\mathrm{pH}$ meter. The corresponding reacted lime was then estimated using the $\mathrm{pH}$ titration curve (using Eq. [5]) and the gasometric method. The amount of residual CCE measured using the gasometric system was plotted against the corresponding residual $\mathrm{CCE}$ estimated by the $\mathrm{pH}$ titration curve for linear regression analysis. In addition, the change in
substrate-pH and residual CCE (gasometric method) were plotted over time.

Effect of $\mathrm{CaCO}_{3}$ incorporation rate on substrate-pH and residual $\mathrm{CaCO}_{3}$ equivalent. As additional $\mathrm{CaCO}_{3}$ is added to a peat substrate, a plateau in the concentration of reacted lime is expected above $\mathrm{pH} 7.0$ because of reduced solubility of $\mathrm{CaCO}_{3}$ at high $\mathrm{pH}$. Application of additional lime beyond that plateau in $\mathrm{pH}$ level is expected to result in an increasing proportion of unreacted lime, which should be measurable as residual CCE. To evaluate whether the gasometric system could quantify these trends, reagent $\mathrm{CaCO}_{3}$ was incorporated into a peat substrate at a rate of $3,6,9$, or $12 \mathrm{~g}$ $\mathrm{CaCO}_{3} \cdot \mathrm{L}^{-1}$ of substrate, and $\mathrm{pH}$ and residual CCE were measured $14 \mathrm{~d}$ later with three replicates per lime rate. Reacted lime was calculated by subtracting applied CCE minus the residual CCE (g CCE $\cdot \mathrm{L}^{-1}$ of substrate).

\section{Results and Discussion}

Validation by incorporating $\mathrm{CaCO}_{3}$ into a preneutralized substrate. Increasing the amount of reagent $\mathrm{CaCO}_{3}$ incorporated into a previously neutralized $70 \%$ peat $+30 \%$ perlite mix resulted in an increased residual CCE (Fig. 3). The ideal recovery rate (calculated as the measured residual CCE/incorporated $\mathrm{CaCO}_{3}$ ) for this procedure would equal $100 \%$. With a $0.05-\mathrm{L}$ sample, the recovery rate ranged from $89 \%$ to $102 \%$ depending on the incorporated $\mathrm{CaCO}_{3}$ concentration compared with $86 \%$ to $95 \%$ for the 0.1-L sample.

This validation experiment assumed that none of the applied $\mathrm{CaCO}_{3}$ reacted with the substrate because the substrate-pH was raised to $\mathrm{pH} 7.35$ with $\mathrm{Ca}(\mathrm{OH})_{2}$ before the $\mathrm{CaCO}_{3}$

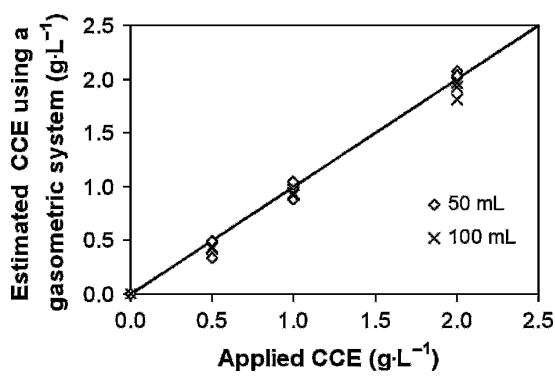

Fig. 3. The relationship between estimated $\mathrm{CaCO}_{3}$ equivalent (CCE) using a gasometric system and the applied CCE in a preneutralized substrate. Reagent $\mathrm{CaCO}_{3}$ was incorporated at three concentrations $(0.5,1.0$, and $2.0 \mathrm{~g}$ per liter of substrate) into a $70 \%$ peat $+30 \%$ perlite substrate that had been previously neutralized to $\mathrm{pH} 7.35$ using reagent $\mathrm{Ca}(\mathrm{OH})_{2}(2.7 \mathrm{~g} \cdot \mathrm{L})$. Data from the 0.05 - and 0.1 -L substrate sample volumes are included. Symbols represent individual measurements. The chart compares applied $\mathrm{CaCO}_{3}$ and estimated residual $\mathrm{CCE}$ for each sample volume. The fitted curves (including 95\% confidence intervals) for the 0.05 - and $0.1-\mathrm{L}$ substrate sample volumes are $\mathrm{y}=1.033 \pm 0.057 \mathrm{x}-0.035 \pm 0.065, \mathrm{r}^{2}=0.994$ $\mathrm{y}=0.959 \pm 0.037 \mathrm{x}-0.023 \pm 0.043, \mathrm{r}^{2}=0.997$ respectively. The solid line represents a $1: 1$ relationship. 
was applied. However, if a portion of the applied $\mathrm{CaCO}_{3}$ did indeed react, that would reduce the recovery rate. We measured the substrate-pH within $6 \mathrm{~h}$ after $\mathrm{CaCO}_{3}$ incorporation, and the substrate-pH increased 0.13 and $0.24 \mathrm{pH}$ units for $\mathrm{CaCO}_{3}$ rates 0.5 and 1.0 $\mathrm{g} \cdot \mathrm{L}^{-1}$, respectively. This indicated that there was partial lime reaction in the preneutralized substrate, which would contribute to some of the error in $\mathrm{CaCO}_{3}$ recovery from Figure 3 .

Validation against a $p H$ titration procedure. The titration of $70 \%$ peat $+30 \%$ perlite with reagent $\mathrm{CaCO}_{3}$ resulted in an approximate linear $\mathrm{pH}$ response with increasing $\mathrm{CaCO}_{3}$ application rate up to a $\mathrm{pH}$ near 7.0 (Fig. 4), which was consistent with the trend observed by Rippy and Nelson (2005). The residual CCE estimated by the $\mathrm{pH}$ titration method was compared with the residual CCE from the gasometric method in Figure 5, and the CCE estimated with both methods had a relationship nearly $1: 1$ with $\mathrm{r}^{2}=0.997$.

Effect of dolomitic limestone on residual $\mathrm{CaCO}_{3}$ equivalent and substrate-pH over time. Figure 6 illustrates how reaction over time of a dolomitic limestone-incorporated rate in CCE at $1.42 \mathrm{~g} \cdot \mathrm{L}^{-1}$ resulted in an increase in substrate- $\mathrm{pH}$ and a corresponding decrease in the remaining residual lime. By

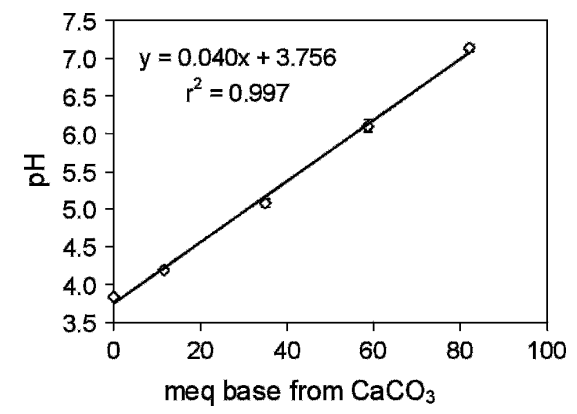

Fig. 4. Titration of $70 \%$ peat $+30 \%$ perlite with reagent $\mathrm{CaCO}_{3}$ showed an approximately linear $\mathrm{pH}$ response with increasing application rate of base up to a $\mathrm{pH}$ near 7.0. Symbol represented the means \pm SE with $\mathrm{n}=3$.

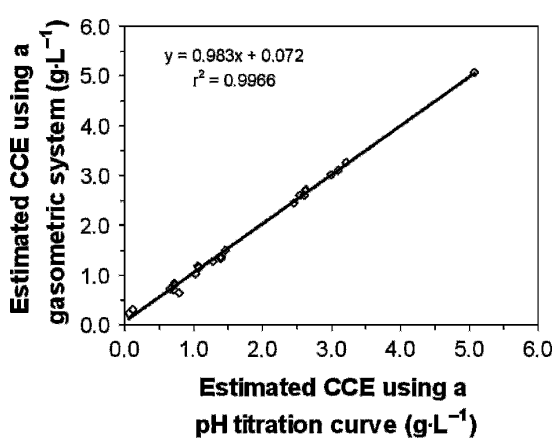

Fig. 5. The relationship between estimated $\mathrm{CaCO}_{3}$ equivalent (CCE) using a gasometric system and the estimated $\mathrm{CCE}$ using a $\mathrm{pH}$ titration curve. Dolomitic limestone was incorporated into the substrate in CCE at 1.42, 2.86, and $5.71 \mathrm{~g} \cdot \mathrm{L}$. Symbols represent individual measurements. Data are included from days $0,1,2$, 8 , and 27. day 27 , substrate-pH had reached $\mathrm{pH} 4.9$, and the lime had reacted completely as indicated by zero detectable residual CCE. Given the demonstrated ability to track change in residual CCE over time, the method could be used during crop production to identify change in the buffering capacity of a substrate (and therefore the potential for rapid and undesirable $\mathrm{pH}$ change).

Effect of applied $\mathrm{CaCO}_{3}$ on substrate-pH and residual $\mathrm{CaCO}_{3}$ equivalent. The gasometric method quantified the expected trend in residual $\mathrm{CCE}$ with increasing applied $\mathrm{CaCO}_{3}$ concentration. Substrate-pH increased from 3.4 with no applied $\mathrm{CaCO}_{3}$ to pH 7.2 after application of $\mathrm{CaCO}_{3}$ at $6 \mathrm{~g} \cdot \mathrm{L}^{-1}$ (Fig. 7A). There was only a slight increase in $\mathrm{pH}$ (from $\mathrm{pH} 7.2$ to 7.5 ) as applied $\mathrm{CaCO}_{3}$ increased from 6 to $12 \mathrm{~g} \cdot \mathrm{L}^{-1}$ of substrate. The measured residual CCE was zero for $\mathrm{CaCO}_{3}$ rate at $3 \mathrm{~g} \cdot \mathrm{L}^{-1}$, and the residual CCE increased from $0.32 \mathrm{~g} \cdot \mathrm{L}^{-1}$ up to $6.08 \mathrm{~g} \cdot \mathrm{L}^{-1}$ after application of $\mathrm{CaCO}_{3}$ from 6 to $12 \mathrm{~g} \cdot \mathrm{L}^{-1}$ (Fig. 7B). Correlated with $\mathrm{pH}$, the calculated amount of reacted lime increased as increasing $\mathrm{CaCO}_{3}$ application rate from 3 to $6 \mathrm{~g} \cdot \mathrm{L}^{-1}$, but increased only slightly for $\mathrm{CaCO}_{3}$ rate between 6 and 12 $\mathrm{g} \cdot \mathrm{L}^{-1}$ (i.e., the amount of reacted lime in $\mathrm{CCE}$ was $5.68,5.77$, and $5.92 \mathrm{~g} \cdot \mathrm{L}^{-1}$ for applied $\mathrm{CaCO}_{3}$ at 6,9 , and $12 \mathrm{~g} \cdot \mathrm{L}^{-1}$, respectively). For a given substrate and limestone source combination, the gasometric method could be used to identify residual CCE at different lime incorporation rates, which would be a useful tool for developing substrates that have high buffering capacity.

Potential sources of error. Generally, the gasometric system could accurately and consistently measure residual lime in CCE from 0.02 up to $16 \mathrm{~g} \cdot \mathrm{L}^{-1}$ of substrate. We found inadequate precision for samples with low alkalinity content (CCE less than $0.05 \mathrm{~g} \cdot \mathrm{L}^{-1}$ ). Temperature and air pressure should be kept stable during experimental runs, ideally under the same conditions as occurred during development of the standard curve. Dry peatbased samples were found to release non- $\mathrm{CO}_{2}$ gas to the system that caused erroneously high $\mathrm{CO}_{2}$ readings (data not shown), which

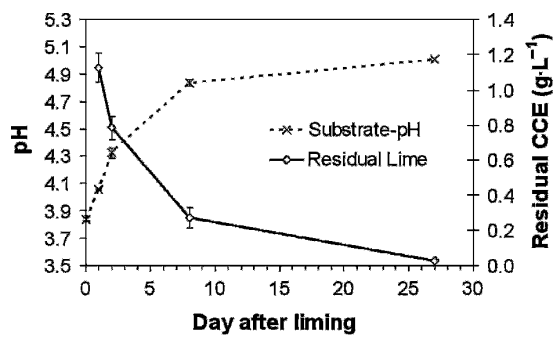

Fig. 6. Changes in residual $\mathrm{CaCO}_{3}$ equivalent (CCE) and corresponding substrate-pH over time after incorporation of a dolomitic limestone (passed through a 100 mesh but retained on a 200 mesh; $75-150 \mu \mathrm{m}$ ) into a $70 \%$ peat + $30 \%$ perlite substrate in CCE at $1.42 \mathrm{~g}$ per liter of substrate. Substrate moisture was maintained at $20 \%$ container capacity at room temperature $\left(22^{\circ} \mathrm{C}\right)$. Symbols represent means of three measurements $\pm \mathrm{SD}$. can be easily corrected by moistening a dry substrate sample with deionized water (1 part water: 1 part dry substrate) and left overnight before it is attached to the gasometric system. Because lime and media components are added to container substrates on a volume basis, rather than by substrate weight, we chose to measure CCE on a per liter basis. For applicable results, it is therefore important that the bulk density of the gasometric sample be prepared at a similar level to the substrate bulk density in a container.

Application of noncarbonate lime materials such as hydrated lime $\left[\mathrm{Ca}(\mathrm{OH})_{2}\right]$ and $\mathrm{CaO}$ could also contribute to $\mathrm{CO}_{2}$ readings when the corresponding substrate- $\mathrm{pH}$ is greater than 7.0 because of potential absorption of $\mathrm{CO}_{2}$ from the air. It is important to note, however, that $\mathrm{pH} 7.0$ is above the normal $\mathrm{pH}$ range for greenhouse crops. We tested the amount of $\mathrm{CO}_{2}$ released using the gasometric method when reagent $\mathrm{Ca}(\mathrm{OH})_{2}$ was applied at different rates in a $70 \%$ peat + $30 \%$ perlite substrate (with corresponding substrate-pH from 3.9 to 8.1 ). There were no $\mathrm{CO}_{2}$ readings observed unless substrate$\mathrm{pH}$ was greater than 7.0 (unpublished data). Carbonate content (as a contaminant) in $\mathrm{Ca}(\mathrm{OH})_{2}$ and bicarbonate arising from $\mathrm{CO}_{2}$ adsorption in the air at high $\mathrm{pH}$ may have contributed to the $\mathrm{CO}_{2}$ readings. Highly soluble carbonate or bicarbonate has a very rapid reaction rate (less than $1 \mathrm{~min}$ ) in the gasometric system based on our observations of nearly instant $\mathrm{CO}_{2}$ gas release when reagent-grade $\mathrm{CaCO}_{3}$ or bicarbonate fertilizer salts were tested.
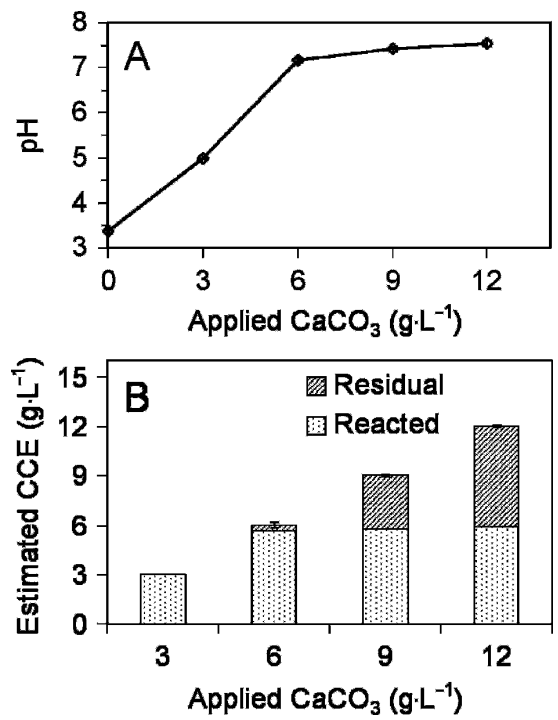

Fig. 7. Substrate-pH response (A) and residual $\mathrm{CaCO}_{3}$ equivalent (CCE) using the gasometric system in a peat substrate and the corresponding reacted $\mathrm{CCE}$ (B) $14 \mathrm{~d}$ after $\mathrm{CaCO}_{3}$ was incorporated into a peat substrate at a rate of $3,6,9$, and $12 \mathrm{~g} \cdot \mathrm{L}^{-1}$ of substrate. Each sample represents the average of three replicates, and error bars represent $95 \%$ confidence intervals. Reacted lime was calculated by subtraction of the applied CCE minus the estimated residual $\mathrm{CCE}\left(\mathrm{g} \cdot \mathrm{L}^{-1}\right.$ of substrate). 
Lime reaction time in $\mathrm{HCl}$ solution is influenced by lime type (calcitic and dolomitic), lime particle size distribution, and chemical purity. We evaluated the reaction rate of 25 commercial horticultural limestones in the gasometric system and found that duration required for $90 \%$ recovery with a $0.2 \mathrm{~g}$ lime sample varied from an average $1.8 \mathrm{~min}$ for calcitic limestone to an average $18 \mathrm{~min}$ for dolomitic limestone. There was considerable variability in reaction time between individual limestone samples with $90 \%$ reaction occurring anywhere from 1 to $50 \mathrm{~min}$ because of factors such as limestone particle size (data not shown).

Substrate components can potentially contribute carbonate, particularly vermiculite. We measured the CCE of five horticultural sources of vermiculite, one source of coir, and five sources of perlite. Measured CCE averaged (mean \pm SD) $2.04 \pm 1.76,0.13 \pm$ 0.08 , and $0.20 \pm 0.18 \mathrm{~g} \cdot \mathrm{L}^{-1}$ for vermiculite, coir, and perlite, respectively. The measured CCE in coir and perlite was very low and would probably be neutralized when these materials are mixed with acidic peat. In contrast, the measured CCE in vermiculite had similar neutralizing characteristics as carbonate limestones and was not completely neutralized when blended with peat. The CCE measured in vermiculite required 20 to $30 \mathrm{~min}$ to reach a complete reaction in the system. The two U.S.-mined vermiculite samples had lower CCE $\left(0.31\right.$ and $\left.0.38 \mathrm{~g} \cdot \mathrm{L}^{-1}\right)$ compared with the South African vermiculite sources $\left(1.48,2.37\right.$, and $\left.2.76 \mathrm{~g} \cdot \mathrm{L}^{-1}\right)$. When a fine-grade South African horticultural vermiculite sample was mixed with the peat at different ratios $(0 \%, 25 \%, 50 \%, 75 \%$, and $100 \%$ by volume) at high moisture (95\% container capacity), substrate-pH at day 7 increased from 3.26 for $100 \%$ peat up to 8.47 for $100 \%$ vermiculite, and measured CCE increased from 0 to $4.95 \mathrm{~g} \cdot \mathrm{L}^{-1}$. Because different sources of vermiculite varied widely in neutralizing power, further research is needed to compare effects of vermiculite source, particle size, and application rate on residual CCE.

Other potential sources of carbonate alkalinity that could affect gasometric measurements in substrates include irrigation water and bicarbonate fertilizers. Both carbonate and bicarbonate will produce one mole of $\mathrm{CO}_{2}$ per mole, although one mole of carbonate has twice the base strength as bicarbonate. The gasometric system is unable to distinguish between bicarbonate and carbonate, except indirectly by reaction time. We have analyzed potassium bicarbonate in the gasometric system (unpublished data) and found that this form of alkalinity reacts completely within a few seconds. In addition, soluble bicarbonate in irrigation water is neutralized rapidly (outside of the gasometric system) when applied to a substrate with $\mathrm{pH}$ below 7 . Argo et al. (1996) found that high alkalinity $\left(\mathrm{CaCO}_{3}\right.$ at $\left.320 \mathrm{mg} \cdot \mathrm{L}^{-1}\right)$ water applied to a peat medium at substrate-pH 5.9 to 6.3 caused a spike in $\mathrm{CO}_{2}$ within 10 min because of reaction with peat acidity, and the bicar- bonate was mostly neutralized within 180 min after the irrigation event.

Substrate $\mathrm{pH}$ buffering can be contributed by noncarbonate sources that would not be measured with the gasometric method, for example, phosphates or substrate cation exchange capacity. However, Argo and Biernbaum (1996) found that the low bulk density of components typically used in container substrates means that residual lime had a greater effect than cation exchange capacity on $\mathrm{pH}$ buffering.

\section{Conclusions and Suggested Protocol}

Residual CCE in a substrate is an important property that should be considered for $\mathrm{pH}$ control and management in greenhouse crop production. The results shown in Figures 6 and 7 indicate that the gasometric system is a useful tool for optimizing lime application rate and management of residual CCE during crop production. For different lime sources, it would be possible to quantify the reacted and residual CCE at a given lime incorporation rate to a particular substrate. It may be possible to identify a desirable minimum residual $\mathrm{CCE}$ for adequate $\mathrm{pH}$ buffering to avoid a rapid $\mathrm{pH}$ drop during production. If residual CCE was found to be close to zero, corrective actions such as a basic drench may be useful for crops sensitive to iron/manganese toxicity at low $\mathrm{pH}$.

Results from the gasometric method were closely matched with those estimated by the validation experiments using preneutralized media or $\mathrm{pH}$ titration. These results suggested the following procedure for CCE determination in a container substrate using the gasometric system:

1. System calibration and standard curve development: The system should be calibrated as shown in Figure 2. A standard $\mathrm{CO}_{2}(\mathrm{~mL})-\mathrm{CaCO}_{3}(\mathrm{~g})$ curve is recommended for $\mathrm{CCE}$ determination if the air temperature and air pressure are stable or, alternatively, the Ideal Gas Law should be used for each experimental run after measurement of the air temperature, air pressure, and volume of evolved $\mathrm{CO}_{2}$ in the gas-measuring burette. To prepare a standard $\mathrm{CO}_{2}(\mathrm{~mL})-\mathrm{CaCO}_{3}(\mathrm{~g})$ curve, weigh reagent-grade $\mathrm{CaCO}_{3}$ samples to the nearest $0.1 \mathrm{mg}$ and place in $1-\mathrm{L}$ decomposition flasks. Sample weights of $0.05,0.10,0.20,0.30$, and $0.40 \mathrm{~g}$ are suggested if the total solution is $0.1 \mathrm{~L}$ of deionized water. Using the same procedure for measuring the volume of $\mathrm{CO}_{2}$ released in the substrate samples, the suggested reaction time is $10 \mathrm{~min}$.

2. Substrate sample size: Measure 0.050 or $0.1 \mathrm{~L}$ to the nearest $1-\mathrm{mL}$ substrate samples and transfer into 1-L decomposition flasks. The recommended substrate sample is $0.1 \mathrm{~L}$ if the expected residual CCE is less than $0.5 \mathrm{~g} \cdot \mathrm{L}^{-1}$ and $0.05 \mathrm{~L}$ substrate if $\mathrm{CCE}$ is larger than
$0.5 \mathrm{~g} \cdot \mathrm{L}^{-1}$. The substrate sample should contain CCE at least $0.05 \mathrm{~g}$ for accuracy.

3. Volume of deionized water and volume of $6 \mathrm{M} \mathrm{HCl}$ : Add $0.075 \mathrm{~L}$ of deionized water into the 1-L decomposition flask that contains the $0.05-\mathrm{L}$ substrate sample, place a magnetic stir bar in the flask, then attach the flask to the gasometric system. After the system is closed, add $0.025 \mathrm{~L}$ of $6 \mathrm{M} \mathrm{HCl}$ into the decomposition flask through the acid-dispensing burette. For a 0.1-L substrate sample, the volumes of deionized water and $6 \mathrm{M} \mathrm{HCl}$ are 0.15 and $0.05 \mathrm{~L}$, respectively.

4. Reaction time: The recommended average time for general grade dolomite and calcite is $30 \mathrm{~min}$. As a general guideline, the experimental run is finished when the $\mathrm{CO}_{2}$ volume reading is stable for at least $5 \mathrm{~min}$.

5. Procedure: In addition to the detailed procedure described in the article by Huang et al. (2007), a magnetic stirrer is introduced into the gasometric system. The sample should be constantly stirred during the lime dissolution period. A heat isolation pad should be placed between the top surface of the stirrer and the bottom of decomposition flask to isolate possible heat from the magnetic stirrer motor.

\section{Literature Cited}

Allison, L.E. and C.D. Moodie. 1965. Carbonate. In: C.A. Black (ed.). Methods of soil analysis. Part 2. ASA, Madison, WI.

Argo, W.R. and J.A. Biernbaum. 1996. The effect of lime, irrigation-water source, and watersoluble fertilizer on the $\mathrm{pH}$ and macronutrient management of container root-media with impatiens. J. Amer. Soc. Hort. Sci. 121:442-452.

Argo, W.R., J.A. Biernbaum, and W.C. Fonteno. 1996. Root medium carbon dioxide and oxygen partial pressures for container grown chrysanthemums. HortScience 31:381-384.

Dreimanis, A. 1962. Quantitative gasometric determination of calcite and dolomite by using Chittick apparatus. J. Sediment. Petrol. 32:520-529.

Goh, T.B., R.J. St. Arnaud, and A.R. Mermut. 1993. Carbonates, p. 177-185. In: M.R. Carter (ed.). Soil sampling and methods of analysis. Canadian Society of Soil Science. Ottawa, Ontario, Canada.

Huang, J.S., P.R. Fisher, and W.R. Argo. 2007. A protocol to quantify the reactivity of carbonate limestone for horticultural substrates. Comm. Soil Sci. Plant. Anal. 38:719-737.

Hülsemann, J. 1966. On the routine analysis of carbonates in unconsolidated sediments. $\mathrm{J}$. Sediment. Petrol. 36:622-625.

Moore, T.J., R.H. Loeppert, L.T. Weat, and C.T. Hallmark. 1987. Routine method for calcium carbonate equivalent of soils. Comm. in Soil Sci. Plant Anal. 18:265-277.

Puustjarvi, V. and R.A. Robertson. 1975. Physical and chemical properties, p. 23-38. In: D.W. Robinson and J.G.D. Lamb (eds.). Peat in horticulture. Academic Press, London.

Rippy, J.F.M. and P.V. Nelson. 2005. Soilless root substrate-pH measurement technique for titration. HortScience 40:201-204. 